artiticial leaves worn on bonnets and head-dresses of course readily becomes detached, and is peculiarly favourably placed for falling upon the face and neck, as well as for inhalation.

When muslin, and especially ball-room dresses, are coloured with this pigment, it adheres but very slightly to the fabric itself, so that in the whirl and maze of the dance it becomes detached in considerable amount, and thus what should be a pleasant pastime and a healthy recreation, becomes converted into what has been recently not inaptly styled "the dance of death." "I apprehend, however, that the danger of arsenical poisoning is not nearly so great to the wearers as to the makers of these arsenical ornaments and dresses.

I am as yet unacquainted with the effects of arsenical paint on health. In this case, also, the dangers, if any, would be to the workmen principally. It is well known that paper-stainers using Scheele's green suffer in the same way as the leaf-makers, being afflicted with sores and excoriations, running from the eyes and nose, and from other disagreeable and injurious consequences.

The practice of colouring lapers and candles with arsenite of copper is highly pernicious, for in this case, during combustion, the arsenic becomes set free, and is diffused through the atmo sphere of the room in the form of arsenious acid.

There is one use of this pigment which is more objectionable and more injurious than that just alluded to, and that is in the coloration of sugar confectionery. Here the pigment is eaten ; the poison is directly introduced into the system, and for the most part into the tender and susceptible stomachs of young children, there to work its poisonous effects. A few years since bushels of sngar confectionery, coloured with arsenite of copper, might have been purchased in London in the course of a single day; but owing to the revelations of THE LANCET, which have been continued through a series of years, this adulteration, though not entirely stopped, has been very considerably checked.

Arsenic is used in the arts in other forms besides arsenite of copper, as in those of arsenite of potash, and arsenious acid in fly papers and cosmetics, and for poisoning wheat. These uses are likewise by no means unattended with danger.

I now pass on to make a few observations on another green pigment much used in the arts-namely, Brunswick green, of which there are three varieties, and which consists of a mixture of chromate of lead and Prussian blue or ferrocyanide of iron. It is used for the same purposes as the arsenite.

Observations are yet wanting as to the effects of this colouring matter upon health. It is therefore very desirable that attention should in future be directed to this point.

Papers, and particularly flock papers, are very frequently dyed with this green. It was also at one time extensively $\mathrm{em}$ ployed to colour sugar confectionery, and is even now sometimes used for that purpose. Of the impropriety, and even danger, of this use of the pigment not a doubt can be entertained.

Another metallic pigment much used, and for all the purposes already enumerated, is chromate of lead, of which one variety is called orange and another lemon chrome. This substance is extensively employed to colour sugar confectionery, so much so that even now it would not be difficult to purchase in the course of a single day as many as fifty articles coloured with this lead pigment. It occurs also frequently in snuffs.

A second preparation of lead frequently met with is the red oxide of lead. This I have found repeatedly in snuff, cayenne, currie powder, and in sugar confectionery.

Various other colouriug matters, in addition to the preceding, are used in the arts, and are even sometimes added to certain articles of consumption. Thus blue stone, or sulphate of copper, is constantly added, for the purpose of greening them, to bottled fruits and vegetables, and also to those preserved in tin cases. In the case of pickles the same object is attained by boiling the vinegar in copper vessels, whereby verdigris, or an acetate of copper, is formed.

Without multiplying illustrations, it is obvious from what has already been stated that much iujury to health must neces. sarily in many cases result from the indiscriminate use of poi sonous metallic colouring matters. I submit, therefore, that the case is one which demands, in the interests of the public health, a full and searching inquiry. The object of such an investigation should be threefold-first, to determine the nature and full extent of the evil ; second, to suggest palliative and preventive measures; and third, to form a basis for moderate and well-considered legislation, which, while on the one hand it should guard the health of the people, on the other should not interfere unnecessarily with manufacturing processes.

Wimpole-street, Cavendish-square, 1863.

\section{ON A CASE OF HYDATIDIFORM OVUM.}

\author{
By J. MOORHEAD, M.A., M.D., Weymouth.
}

As the opinion of the profession at large with regard to the nature and pathology of so-called uterine hydatids is still unsettled, the following contribution may be deemed worthy of publication. It will serve to illustrate the symptomatology of this morbid development, as well as to corroborate novel views recently put forth on this interesting subject.

On the 24th September, 1862, I was requested to visit Mrs. $G$ - a respectable married female, aged fifty, who was suffering from great irritability of stomach. Though naturally of a stout habit, she was somewhat emaciated, and appeared anæmic. On inquiry, it was ascertained that about the begin. ning of August her appetite, which had been previousily good, became impaired, and in a short time nausea and vomiting super. vened, almost every article of food being rejected soon after being swallowed. These symptoms, accompanied by a great sense of oppression at the præcordia, were present almost throughout the entire day. The sickness persisting, she states that on the 12 th September she took for its relief a wineglassful of the infusion of ground-ivy (Glechoma hederacea), which she bad heard from some of her female friends was a valuable remedy in such cases. On the same day she consulted a physician, who prescribed a mixture containing chiefly chlorodyne. On the motning of the 13 th she took another draught of ground-ivy, and in the course of the day two doses of the mixture, each of which, however was almost instantly rejected. Towards evening she received a shock by a sudden knock at her door, and shortly after a sanguineous vaginal discharge took place, followed by a smals clot. During the interval that elapsed until she consulted me on the 24 th, she states that the bloody discharge occasionally recurred, accompanied by some watery fluid, which came away in gushes with sneezing, coughing, or retching. The gastric symptoms also persis:ed with mu.h severity, and she began to suffer in her general health. She informed me that she had had four children at full term and three miscarriages, and that she had not been preguant for the last twenty years, during which period, however, she had regularly menstruated every four weeks until the 25th July, after which date nothing appeared until the time of the hæmorrhage above referred to.

When I first saw the patient, her tongue was thinly coated with a moist white fur ; there was pain of stomach, though not considerable, attended with a sense of oppression, also slight tenderness of epigastrium on deep pressure ; vomiting occurred almost after every meal. As the gushes of water which occasionally took place were supposed by the patient to come from the bladder, and the irregularities of the catamenia might be attributed to her advanced age, $I$ then regarded the case as one of dyspepsia, and accordingly prescribed alkalies with sedatives, consisting of dilute hydrocyanic acid, chloric eth $x$, chlorodyne, oxalate of cerium, et hoc genus omne. Though each of these remedies aff,rded temporary relief, the sickness soon returned with its rristine severity, and consequently, on October lst, a full examination of the abdomen wis instituted. There was still slight pain on pressure over epigastrium; but the most notable feature was a hard globular tumour, about the size of a child's head, occupying the hypogastrium, and extending as high as the umbilicus. This tumour, from its situation and relations, was evidently uterine, and to my mind at once accounted for the constant sickness, which was clearly sympathetic. As there had been slight hæmorrhage during the few aays previous, the idea of polypus or fibrous tumour of uterus sugsested itself, pregnancy having been left out of consideration, as the patient had not borne any children for twenty years. An internal examination was proposed, but she would not then submit to it, and begged me to try the effect of medicine a little longer. Accordingly, sinapisms were applied to the epigas:rium, and sedative drugs again resorted to for some days; but as the vomiting still continued, and debility increased, she at length consented to an examination per vaginam, which was made on the 8 th October.

The cervix uteri was found to project into the vagina; the os was patulous, so as easily to admit the finger; and when this was pushed into the uterine cavity, the latter was found filled with a substance which was soft and placenta like to the feel. As the finger, on being withdrawn, was covered with blood, the patient was directed to use the tepid-water douche and to keep in the recumbent posture. A few hours afterwards, 
however, strong uterine pains set in, which soon expelled, with slight bæmorrhage, a vesicular mass nearly balf tilling a washhand-basin. I was immediately sent for, but on my arrival found the mass in question so broken up by the attendants while removing it to the basin, that to recognise its constituent parts was almost impossible. I discovered, however, on careful examination, some portions enveloped by the decidua, which was covered in two places with a thin lamina of coagulum; but the distinction of chorion and amuion could not be recognised, their places being occupied by a stringy resicular substance nearly three inches in thickness. What appeared to have been a small cavity was discovered, but there was not a trace of embryo. The vesicular bodies were generally about the size of currants, though a few were larger. It is almost needless to state that the sickness and all other distressing symptoms at once disappeared, and the patient made a rapid recovery.

Remarks. - The foreyoing case, while it bears a striking resemblance to one recently reported by Dr. Graily Hewitt in The Lanoers, affords corroborative testimony to the correctness of the views advanced by that distinguished obstetrist in the first volume of the "Obstetrical Transactions." Several of the so.called hydatids, when examined under the microscope, exhibited numerous nucleated cells similar to ihose presented by the chorion villi, thereby inducing the inference that the cystlike bodies were merely hypertrophied and oedematous portions of natural structures.

With respect to the mode of origin of this vesicular degeneration of chorion there is considerable diversity of opinion. Some think the transformation the result of perverted developmental force, and that it ultimately leads to the death of the embryo; whilst others, and especially Dr. Craily Hewitt, believe the latter event to be the first link in the chain of pathological sequence. Without entering at length into the controversy, I may observe that the circumstances of this case favour the opinion of Dr. Hewitt, and, when regarded in the light of his published observations on the subject, admit of easy expla. nation. As menstruation ceased on July 25th, and nause began early in August, it may be assumed that conception took place shortly after the former date, and that foetal development went on normally until September 13th, when contraction of the uterus--induced either by the ground-ivy or the sudden shock-partially separated the ovum from its walls and gave rise to the hæmorrhage. This separation, though it destroyed the life of the embryo, was not, however, sufficient to produce abortion, and consequently the chorionic processes still embedded in the decidua con'inued to grow whilst they degenarated into the cyst-like bodies afterwards expelled. As the embryo at its death could have been only about seven weeks old, and therefore probably about the size of a small bee, it is not surprising that no traces of its existence were discovered more than three weeks subsequently.

The rapid enlargement of the uterus characteristic of so-called hydatid growth was well displayed in this case, as the organ had attained to the dimensions nsal at the sixth month of gestation, though its contents could not have begun their de. velopment earlier than ten or eleven weeks previously. The entire absence of suspicion of pregnancy on the part of the patient, coupled with her adranced age, at first rendered the case obscure, but its termination satisfactorily removed all the difficulties previously surrounding it.

Weymouih, 1863.

The Mrdical Departinent of the ITAlian Army, which in 1858 numbered 155 surgeons, is now increased to 755. This is an incident which onght to afford matter of grave reflection to the authorities in this country. Whilst they are underrating the value of the non-combatant military officers, the Italians are exercising a wise discretion by improving their position. The recent lessons that the campaigns in China and India onght to have taught us appear to have been lost upon the medical director of the army. $I_{t}$ is in the power of the junior members of our profession to remedy a crying evil. Any gentlemen who contemplates joiring the army medical staff of this country should reflect seriously on the position he is to occupy, and the emoluments which he has to receive. We re gret that neither of these is of such a character as we could recommend to the favourable notice of our junior brethren. Supply and demand, in a commercial sense, are said to "rule" the market. Why should it not be so when the interest of a large professional body is concerned? Unly let the "supply" be below the "demand," and the authorities will be placed in a position of diffculty. That righteous claim which is not yielded on principles of justice will be granted to the inexorable logic of necessity. a Mirror

OF THE PRACTICE OF

\section{MEDICINE AND SURGER IN THE}

HOSPITALS OF LONDON.

Nulla est alia pro certo noscendi via, nisi quam plurimas et morborum et parare-Mongatia. De Sed.et Caus. Horb., lib. 14. Procmium.

\section{ST. BARTHOLOMEW'S HOSPITAL.}

THE RODENT ULCER OF JACOB, AFFECTING THE RIGHT AURICLE OF A BOY, AFTER A WOUND WITH A BARBER'S SCISSORS; REMOVAL OF THE PART.

(Under the care of Mr. WORMALD.)

TAKING the immense experience afforded by the large hos. pitals as our guide, we should say that some of the more serious diseases are rarely to be seen in the external ear; and yet writers on diseases of the ear s'ate that the auricle is sub. ject to a variety of maladies. We have noticed from time to time instances of tumours, but rarely examples of malignant disease, although we recollect seeing an instance at the Cancer Hospital, a few years back, under Mr. Weeden Cooke's care, wherein the auricle was extensively affected with carcinoma. On referring to the practical manual on the "Ear in Health and Disease," we find its author states that carcinomatous and lupoid affections of the auricle are occasionally met with generally in the form of ulceration. The former goes on to the destruction of the entire organ, and ultimately of life; of the latter he had not met with any instance. The lupoid disease, then, or "rodent ulcer," as it is now recognised, must be extremely rare in this part of the body. We have the opportunity of recording a case in the above hospital, under the care of Mr. Wormald. Curiously enough, another instance of it occurred to one of the surgeons of the same hospital, in private practice, in 1858 -namely, to Mr. Paget. The patient was a gentleman, aged fifty five, who had been the subject of rodent ulcer on the ear for seven years, and it was only stayed by removal of the part.

An objection misht be taken to the character of the disease in Mr. Wormald's patient because of his age (sixteen years), as no example that we know of has been recorded wherein the disease had appeared in youths of either sex; still it had all the physical characters so far as naked-eye appearances went.

The history which Mr. Wormald gave was, that two years and a half ago the lad (William M-) had his hair cut by a barber, who accidentally snipped the back of his right ear. Inflammation followed, with enlargement, ulceration, and excavation of the back part of the auricle, which had resisted every mode adopted to bring about the healing process. Ho was admitted into Darker ward on January $20 \mathrm{th}$. Looking at the ear in front, several puckers and irregularities were noticed in the anti.helix, and also at the upper mirgin of the helix itself. On turning the patient round, so that the back of the ear could be seen, a large excavation was observed that would admit a split walnut, which seemed to be bounded on one side by the skin, and on the other by the cartilage of the ear; the margins of this cavity had the peculiar look of the rodent ulcer, and the cavity itself was ulcerated.

Chloroform was given on the 31 st of January, when all the affected part was cut away, excepting the superior and anterior borders of the auricle and the lobulus and anti-tragus, which were subsequently brought into contact very neatly by silver sutures, thus giving to the patient an ear about a third the size of the natural one.

The healing process now went on most favourably, for in a fortnight nnion was complete; and, with the exception of a very small surface to cicatrize over, the boy may be said to be convalescent.

There were no enlarged glands in the neck or elsewhere be fore the operation, which dispels the idea at one time enter. tained that the disease might have been epithelioma.

Whilst on the subject, we may observe that this disease was first described by Dr. Jacob, of Dublin, in 1827, in the fourth 